\title{
U-SEA: A Learning Environment Ubiquitous Using Cloud Computing
}

\author{
http://dx.doi.org/10.3991/ijet.v7i1.1838 \\ S. D. Piovesan, E .M .H. Amaral, C .P. B. Arenhardt and R. D. Medina \\ Universidade Federal de Santa Maria - UFSM, Santa Maria, Brasil
}

\begin{abstract}
The spread use of virtual learning environments presents a great potential for the development of applications which meet educational area needs. In view of the importance of a more dynamic implementation and that it will be able to continuously adapt to the students needs, it was proposed and developed the U-SEA (System of Teaching Adapted Ubiquitous). A software built on the basis of virtual learning environment Moodle, having as main purpose the adaptation to the computational context of the student, glimpsing characteristic techniques such as the environment suitability of the user's connection speed, provided with an infrastructure for Cloud Computing.
\end{abstract}

\section{Index Terms—Cloud Computing, U-learning}

\section{INTRODUCTION}

The use of Virtual Learning Environments (VLEs) in the academic world has become common, both in distance learning courses and in attendance courses. Before that, to make the appropriate environment for the student, considering his /her individual characteristic is a need today. In this field, it is inserted the ubiquitous learning (ULearning), which allows the access to educational resources with full mobility and system adaptation to the students' computational context. In this scenario, the Virtual Learning Environments are in a constant development and adaptation process, and they can quote: the AulaNet [1], Teleduc [16] and Moodle [8]. Within this scenario this article aims to propose a new application for these environments where these students in addition to having the device facilities of mobility and adaptability through the Mle-Moodle will have an environment which will adjust to their computational context, making the material appropriate to different connection speed.

The Cloud or Cloud Computing emerges as a technology to improve and make the computer resources more efficient, through features such as availability, elasticity and adaptability of services, where the user can operate remotely his/her programs and have at his/her disposal a greater capacity for storage and processing, without the need of having more expensive equipment, because his/her data will be available in the cloud.

The problem of increasing the Internet size and complexity and also the user technological diversity brings the need to treat each connection to the environment as an individual and specialized basis, identifying the profile and developing applications in virtual environments able to adapt.

Under this perspective, several studies have been developed to adapt the VLEs existing to the user's context, as the case with the Mle-Moodle, AulaNetM, the AdaptWeb of Sloodle, the LIP and the Cule [4]. Yet, the SEDECA [9] was developed to perform a cognitive style analysis, allowing the development of a framework for the adaptation of the virtual learning environment mobile MleMoodle to different cognitive students' styles, demonstrating the advantages of adapted environments to the teaching-learning process. However, none of them is adapting the content to the student's computational context.

The existing VLEs have static platforms, allowing only the content selection and tools that will be used by teachers, without taking into account individual characteristics of the students who make use of the environment. From the research carried out by means of a speedometer integrated to the VLE Moodle School Cietec (Technical School in Santa Maria) several ways were noticed in which the students could access the environment, through mobile devices or computers desktops and the great speed variation of the connection, showing that student's computational context is quite varied. The differences in the students' computational context brings a problem to the use of VLEs, because with lower speed connection appears problems to access larger files, therefore they take a long time to be fully loaded, transferred or opened. From these shortcomings observed in the literature, this article presents the adaptation of environment Moodle to the user computational context.

This article is structured as follows: section 2 presents the definitions of Cloud Computing; section 3 presents the VLE Mle-Moodle; section 4 presents the Environments Context-sensitive; the methodology for developing the application U-SEA is presented in section 5; section 6 presents the Moodle U-SEA and the final considerations are presented in section 7 .

\section{Cloud COMPuting}

This is a new technology trend that is intended to be comprehensive and provide services to the masses that go from the final user that hosts personal documents on the Internet to companies that outsource the entire IT infrastructure [2]. Computing in the Cloud is justified by the fact that the resources of both software and hardware becoming obsolete in a short period of time, making the use of computational platforms to third parties is the ideal solution for the problems of infrastructure. To use their systems the user does not need senior computing resources, neither software nor hardware, reducing the cost of the machinery acquisition [7].

The infrastructure in the environment of Cloud Computing usually consists of several physical machines connected by means of a network. Each computer has the same software configurations, but it can vary the ability of hardware in terms of processing power, storage, and 
memory. Within each piece of equipment there is a variable number of virtual machines or in implementation, according to the physic machine [15].

As For the model of deployment, the clouds may be: [7]

- Private: The infrastructure of the cloud, is exclusive to an organization, and is administered by the company or by third parties;

- Public: The infrastructure is made available to the public in general, and that can be accessed by any user since he/she knows the location;

- Community: the cloud is shared by several companies, sharing interests such as: mission, safety requirements, and flexibility;

- Hybrid: Composition between two or more types of clouds, linked by a standardized technology or owner that allows portability of data and applications.

The technology of Cloud Computing has three service models which may be available, and these are setting their standard architecture [7], they are:

- SaaS: It is the software as a service, provides software systems with specific purposes which is available for the user via the internet;

- PaaS: It is a platform service; it offers a high-level infrastructure for deployment and testing;

- IaaS: It is an infrastructure as a service, it is responsible for providing all the necessary infrastructure for the Saas and country.

In the educational area the usage of the Cloud technology is justified by the fact that the information can be accessed from any place, the elasticity of resources and of wide access via personal computers, smartphones or PDAs. Currently, there are several applications which allow the creation of an infrastructure for cloud, among them: Amazon Web Service, Google App Engine and the Eucalyptus platform, chosen for this project.

\section{A. Eucalyptus}

The Cloud Computation involves a large amount of concepts and technologies, and the solution used for the deployment of the cloud U-SEA was the project Eucalyptus. This is an implementation of open code that allows the creation of a compatible infrastructure, so that the users can experience the Cloud [6]. The architecture of Eucalyptus is simple, flexible and modular and contains a hierarchy that shows the common resources of the environment.

The Eucalyptus aims at providing a tool for research and the development of technologies for Cloud, with a simple implementation, using tools for administration and aid the management of the system and the users, with the capacity to configure several clusters [7].

\section{VLE MLE-MOODLE}

The Mle-Moodle is a system designed to operate on mobile devices such as telephones, PDAs, smartphones and tablets to help m-learning system. It has code free source and it is free of charge, in addition to having the possibility of adaptation. The access to the Mle-Moodle can be performed through any browser on any cell phone, but you can also use the MLE-Client, which is a module especially developed for the process of learning with mobile devices. As these environments (the Mle-Moodle and the Moodle) are integrated, students have the possibil- ity to study on cells and then continue their studies on their desktop computer [8].

\section{CONTEXT-SENSITIVE ENVIRONMENTS}

There are several ideas for sensitivity to the context, in one of these definitions; context is defined as information that can be used to characterize the situation of an entity [3].

The sensitivity to the context refers to the need of the environment to be sensitive to the changes that occur, presenting an adaptive character [13]. In sensitive computing to the context each modification may require the initiation of a series of measures taken to maintain full functionality, since it needs to adapt to the needs of the user.

Each student accesses the VLE under certain conditions, which may be at home or in another environment, using a personal computer or a mobile device, it may have acquired knowledge from other sources or not to have any knowledge about the content, part of the activities can or not be carried out [13]. Finally, each student has his/her situation, very individually, determined and, then to determine these variables that can directly interfere with the student's learning is a very important task.

According to [14], there are basically four categories of context:

- Computational Context: relates to the network, connectivity, cost of communication, bandwidth, and other resources such as: printers and stations;

- User's Context: refers to the user profile, location, speed, and people close to him/her, social situation and state of mind;

- Physical Context: refers to luminosity, temperature and humidity;

- Context of Time: refers to the time of day, any date or time of year.

Sensitivity to the Context refers to everything that occurs around the user, and that influences the way he/she interacts with the environment and with other people. For ubiquitous computing, context sensitivity is similar, where computing systems can understand the context and interact with him/her [3].

This work proposes the adaptation of the VLE Moodle and the Module Mle- Moodle to computational context, available through an infrastructure for Cloud Computing, in order to select the materials and tools suitable for each student connection speed, making the Moodle environment u-learning.

\section{A. U-Learning Environments}

In the last decade, the studies on u-learning (ubiquitous learning) brought new opportunities and new challenges. Among the studies can be cited: AdaptWeb, Conference Assistant [3], Sedentas [5] and CampusAware [17].. The paradigm of Ubiquitous Computing, originally proposed by Mark Weiser in the 1990s, gave rise to a new form of computing. In this new form, the computer is offered in any place, all the time and in a transparent manner. Then be understood by u-learning or ubiquitous learning as a repository of information, accessed by any user, in different situations [13].

Environments (u-learning aims to turn the traditional environments of ODL, generally static and which have 
content, structure and static presentation in an environment with features that allow the adaptation of this environment to specific situation experienced by the user at each time gap [13].

\section{Methodology}

This research is part of a set of work carried out on the adaptation of mobile virtual environments. Figure 1 shows the infrastructure available for the environment USEA.

It delegates to software the autonomy in decision about the materials and tools that will be available. The agent receives the task of solving, monitoring the environment for the application, choosing materials and compatible tools and making it available. In the layer of Communication, the proposed architecture by the Agent of Adaptation which has the function of handling the information carried out in the layer of Interface by the students, providing the appropriate material. This Agent will communicate with the Bank System Manager of Oracle's Relational Data Base Management System) and adjust the environment for each student. The identification of the student connection speed will indicate which content and what tools will be made available in their access to the environment. The material to be used by the students will be stored in separate categories by making the environment fully personalized, being that the student only a search results page will open the ideal files for their connection speed. Figure 2 shows the architecture framework U-SEA.

The infrastructure of the cloud made available for the development of the U-SEA, is based on nine computers, with the following format: a gateway, which allows to access to the environment through the network; a server with the functions of cloud controller, cluster controller and storage controller and; seven machines serving node controller, which provides the processing of the cloud. All machines used in this environment, such as node controllers, possess the technology of native virtualization in hardware, being six computers with Dual Core processors and a Quad Core processor, totaling a maximum of sixteen nuclei in the cloud computing, which allows a degree of availability and agility. Figure 3 presents the infrastructure of the cloud.

This environment of Cloud Computing is implemented with Eucalyptus technology, under a platform Ubuntu Linux. For the use of the U-SEA in the environment, it was created an instance in Linux, for the installation of Moodle adapted to the application. Figure 4 shows the screen of Eucalyptus, showing the number of cores or processors available for loading of the instances in the cloud.

The deployment model of cloud computing is private, and the service model is SaaS type, they have the objective of making it easier and more accessible the provision of resources for the students. VLE Moodle U-SEA is installed on the server along the other work already developed for the Moodle, SEDECA and Detector of Plagiarism.

For the development of the Agent was used JavaScript language, along with the language PHP, the same resources for programming used for the implementation of VLE Moodle. The system updates the record of speeds at every minute, with the intention of leaving the material always appropriate.
For the validation of the speedometer integrated to Moodle U-SEA was used Mozilla Firefox browser with the Firebug plugin. Figure 5 shows the screen of the Mozilla Firefox browser with the plugin installed Firebug comparing the speedometer of the environment with the meter plugin Firebug.

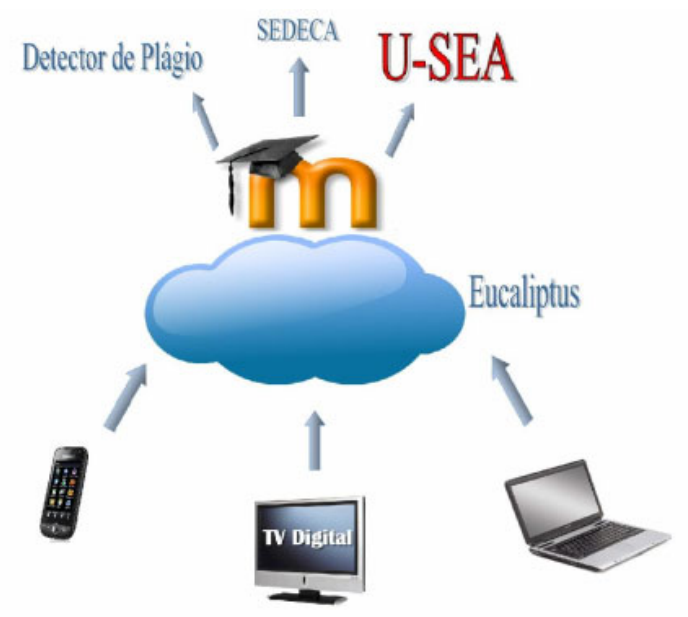

Figure 1. Infrastructure U-SEA

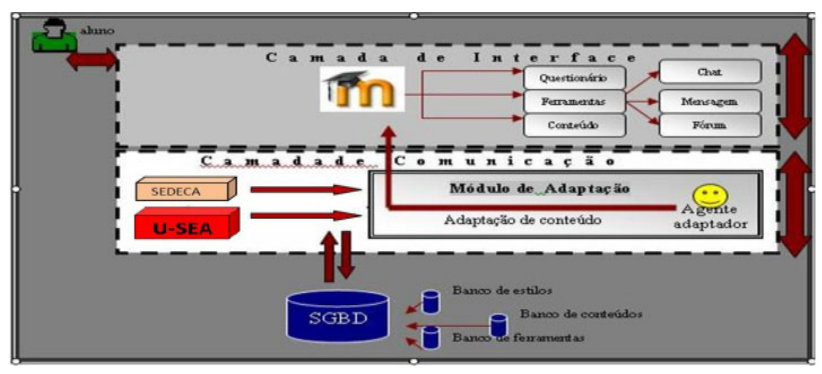

Figure 2. Architecture of the Framework U-SEA.

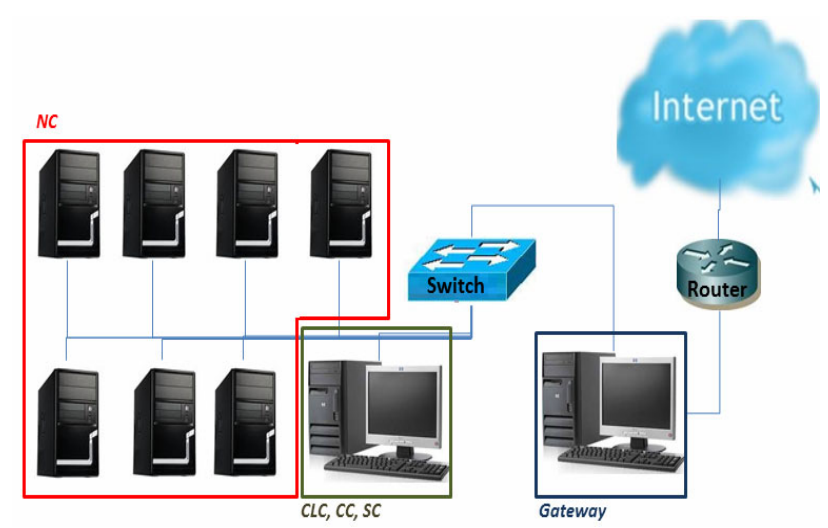

Figure 3. Infrastructure in the Framework U-SEA.

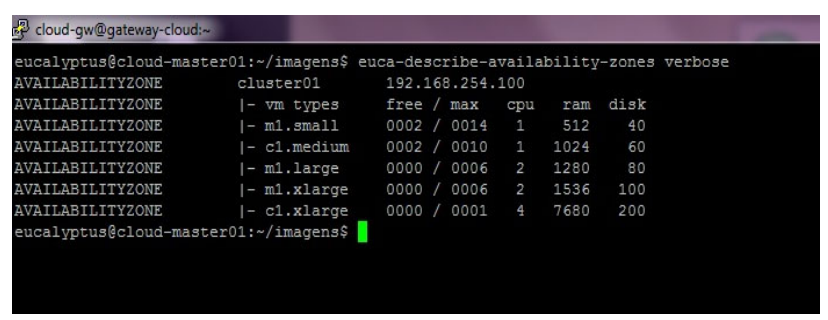

Figure 4. Number of instances available in the cloud. 


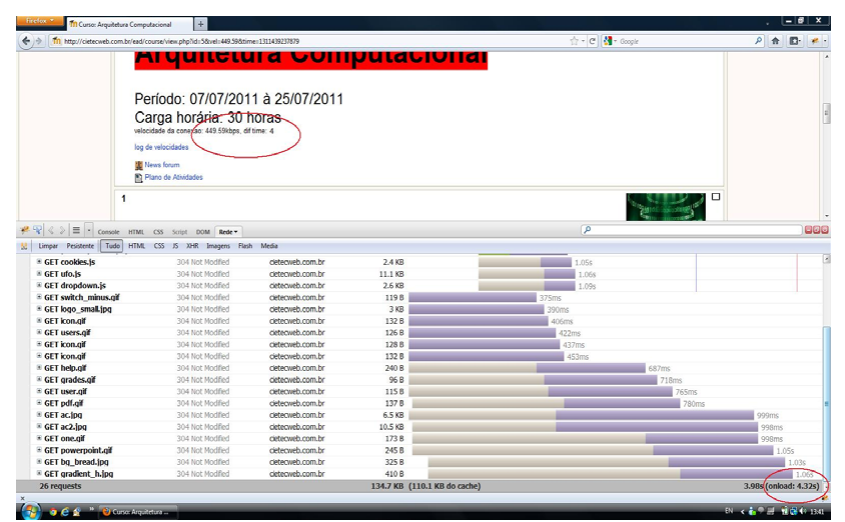

Figure 5. Mozilla Firefox with the Firebug plugin

\section{MOODLE U-SEA}

According to Pereira, "We are not all equal, as well as the areas of knowledge are equally so. This way, we have a lot to search for the teaching-learning process that is mediated by platforms VLEs, appropriate to their target audience" (Pereira, 2007).

The specific objective of the development of the U-SEA and provide an adaptive environment for both desktop computers and for mobile devices by providing a suitable environment for computational context of the student, through the adaptation of the content and available interface, according to the connection speed.

The U-SEA operates in a transparent manner to the user, when the student enters in the environment, this apparently does not change, having characteristics of ulearning software. When the student accesses the course, the system verifies his/her connection speed and provides the materials that are suitable for use in accordance to the identified network. The U-SEA also provides the tools that will be shown during the use of the application, as an example, in slow connections the chats are not available, making the navigation and the interaction more quick and appropriate. The adapted environment stores the speeds of the student's connection and the adapted material that were accessed, making it possible the study of the student's profile by providing an improvement in the quality of the lessons in the distance modality.

For the speed measurement, when the user clicks on the course, the Agent sends a file of $100 \mathrm{~Kb}$, and together to the start of the transfer of this file is initiated a stopwatch in order to calculate the time for the full transmission of such file. Taking these data, the Agent performs a simple calculation of file size on the time, generating a speed that is presented to the user. These data are saved in a log and made available in the environment. This file is in XML (Extensible Markup Language) and contains, in addition to the user speed, the IP address (Internet Protocol) to the computer and the date that the environment was accessed, thus making it possible for detailed analysis of the obtained data. The user does not have access to this file which is transferred to his/her machine, because the same is sent and loaded directly to the memory of the computer.

The validation of the Moodle U-SEA was performed at Technical School Cietec, at the discipline of Computer Architecture, where the data was collected to be presented in this article. Figure 6 shows the screen of Moodle USEA showing the connection speed of the user and the materials that are available for connection.

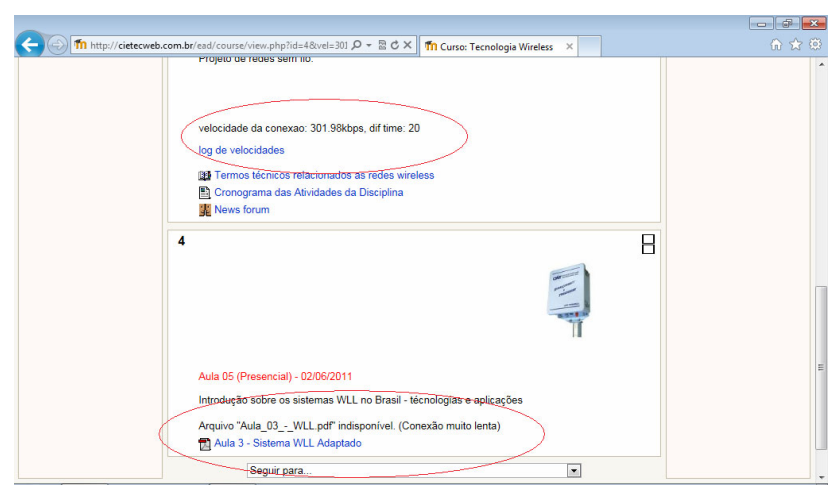

Figure 6. Moodle U-SEA

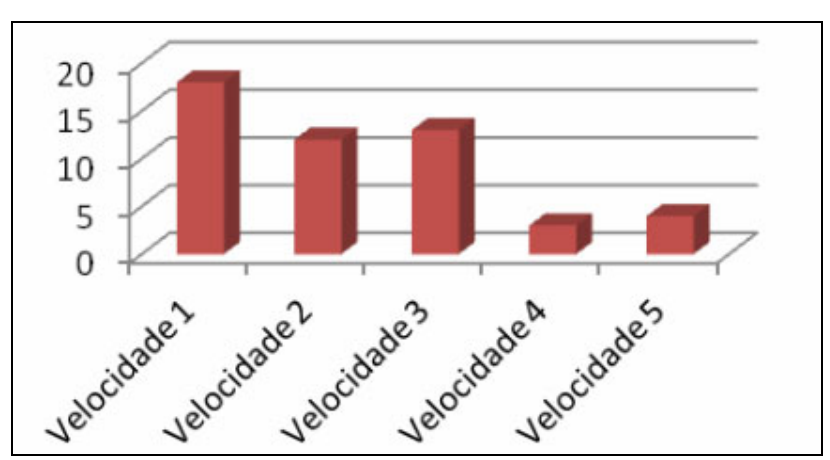

Legenda:

Velocidade 1: Até $500 \mathrm{Kbps}$

Velocidade 2: De 500 Kbps até $1000 \mathrm{Kbps}$

Velocidade 3: De $1000 \mathrm{Kbps}$ até $1500 \mathrm{Kbps}$

Velocidade 4: De 1500 Kbps até $2000 \mathrm{Kbps}$

Velocidade 5: Acima de $2000 \mathrm{Kbps}$

Figure 7. Graph of Speed Variation

- Alunos que Acessaram Materiais Adaptados

Alunos que Acessaram Materiais Normais

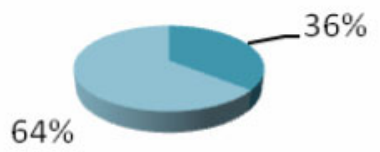

Figure 8. Graph showing the number of students who exploited adapted material

Due to the large amount of data collected and stored in the file of logs of Moodle U-SEA, the fifty first accesses that occurred were selected in the period of July 05, 2011 until July 15, 2011, as a sample for analysis presented here. Figure 7 displays the graph showing the great variation of speed that the students used to access the discipline.

Figure 8 shows the graph with the number of students who exploited content adapted during the period. The graph shows that the selected sample, $36 \%$ of the accessions showed a computational context that required the tools and materials which were appropriate for a better use of VLE.

Figure 9 shows the screen of Moodle U-SEA being accessed by mobile devices, being that the machine used was the Nokia 5233 with wireless connection to OI service provider and Figure 10 shows the equipment screen Motorola Q11 by accessing the Moodle U-SEA through the connection to smartphone of Claro Cell Phone Company. 


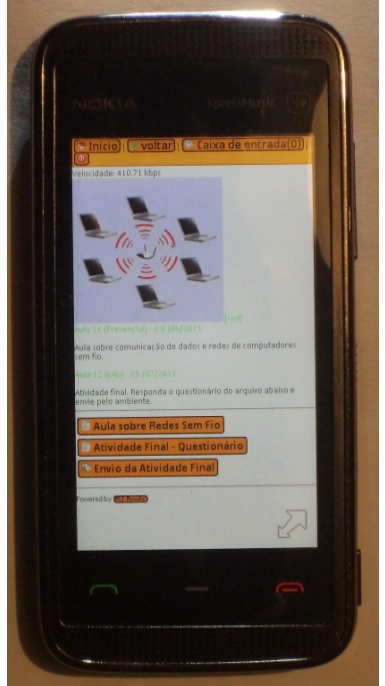

Figure 9. . .Nokia 5233

\section{FINAL CONSIDERATIONS}

The computation is moving to a new modality, where all the services for data storage applications will be available at all times and at any place where the user has access to the Internet, appropriately and aware of their context. During the research of this work it was noted that the increase in the use of mobile VLEs, a fact that levers and facilitates the development of courses in the DL modality, which shows clearly the need for the availability of tools that make the adopted practices in this modality of education really effective. In this context they are extremely necessary to didactic material be appropriate to the student, the materials are of good quality and the whole structure of this environment to work in order to provide an appropriate environment for the structure of teaching and learning. This panorama shows the need for the improvement of the VLEs and their adaptation to the requirements to their users. The main contribution of this work and the presentation of a totally adaptive environment, taking into account the context of computational students that access the VLE Moodle U-SEA. The characteristics of availability through the technology of Cloud Computing, the adaptation of the content for the mobile devices of the students and the adequacy of the tools and content for the computational context of the student through the connection speedometer integrated to VLE make VLE Moodle U-SEA u-learning software.

\section{REFERENCES}

[1] Aulanet. Available at: <http://www.eduweb.com.br/elearning tecnologia.asp $>$ Accessed May 2010

[2] Buyya, R., Yeo, C. S., Venugopal, S., Broberg, J., and Brandic, I. Cloud computing and emerging it platforms: Vision, hype, and reality for delivering computing as the $5^{\text {th }}$ utility. 2009. Future Gener. Comput. Syst., 25(6):599-616. http://dx.doi.org/10.1016/ j.future.2008.12.001

[3] Dey, A. K., Abowd, G. D. “Towards a Better Understanding of Context and Context-Awareness”. Technical Report GIT-GVU-9922. College of Computing. Georgia Institute of Technology. 1999, Atlanta.

[4] Filippo, D. et al. AulaNetM: Extensão do Serviço de Conferências do AulaNet destinada a usuários de PDAs. In: Anais do XVI Simpósio Brasileiro de Informática naEducação - SBIE, 2005, Juiz de Fora, MG, pp. 623-633.

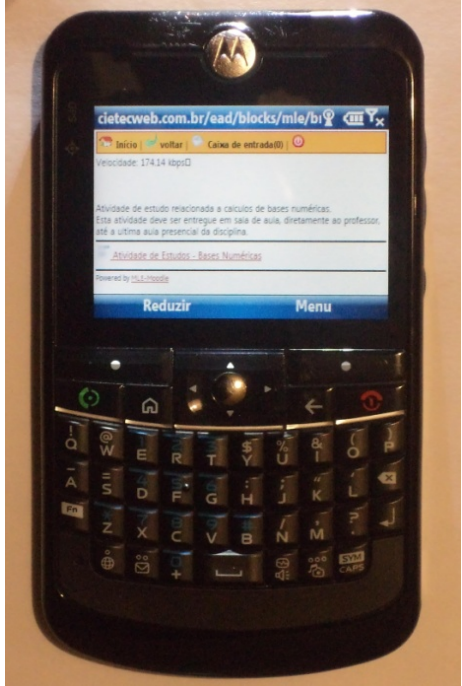

Figure 10. Motorola Q11

[5] Horvitz E. (1999). Principles of Mixed-Initiative User Interfaces. ACM SIGCHI Conference Human Factors in Computing Systems. ACM Press. New York. May. Pages 159-166.

[6] Liu, S., Liang, Y., and Brooks, M. (2007). Eucalyptus: a web service-enabled einfrastructure. In CASCON '07: Proceedings of the 2007 conference of the center for advanced studies on Collaborative research, pages 1-11, New York, NY, USA. ACM.

[7] Machado, J.C.; Moreira, L., O.; Sousa,F.,R.,C.; Computação em Nuvem: Conceitos, Tecnologias, Aplicações e Desafios. In: ERCEMAPI, 2010.

[8] Mle-Moodle - end Users. MLE-Moodle. Available at: $<$ http://mle.sourceforge.net/mlemoodle/index.php?lang=en>. Accessed May 2010.

[9] Mozzaquatro, P. M. Modelagem de um Framework para Adaptação de Ambientes Virtuais de Aprendizagem Móveis aos Diferentes Estilos Cognitivos, no estado do Rio Grande do Sul: Santa Maria/UFSM, 2010. Dissertação de Mestrado.

[10] Net Combo. Available at: <http://www.netcombo.com.br/static/ html/assinenetcombo/?gclid=CK7tlOyO KgCFYjt7QodyS3KTw $>$ Accessed 2011.

[11] OI. Available at : <http://novaoi.oi.com.br/portal/site/NovaOi/men uitem.74476e871edc8be9f72f820349cc02a0/?gnextoid=f8aeef00f6 948210VgnVCM10000021d0200aRCRD\&STATE=21|RS|Rio Grande do Sul> Acesso em 2011.

[12] Pereira, A.T.C.; Schmitt ,V.; Dias, M.R. A. C. AVA -Ambientes Virtuais de Aprendizagem em diferentes contextos. 2007. Editora Ciência Moderna , Rio de Janeiro.

[13] Pernas, A. M. et. al. Um Ambiente EAD Adaptativo Considerando o Contexto do Usuário. 2009.

[14] Schilit, W. N. A "System for Context-Aware Mobile Computing." Ph.D. Thesis, Columbia University, 1995, New York.

[15] Soror, A. A., Minhas, U. F., Aboulnaga, A., Salem, K., Kokosielis, P., and Kamath, S.. Automatic virtual machine configuration for database workloads. 2010. ACM Trans. Database Syst., 35(1):147. http://dx.doi.org/10.1145/1670243.1670250

[16] TelEduc. Available at: <http://www.teleduc.org.br/>. Accessed August 2009.

[17] Burrell, J.; Gay, G.; Kubo, K.; Farina, N. (2002). Context-Aware Computing: A test case. 4th international conference on Ubiquitous Computing. Göteborg, Sweden. September-October. Pages 115.

\section{AUTHORS}

S. D. Piovesan, E .M .H. Amaral, C .P. B. Arenhardt and R. D. Medina are with Universidade Federal de Santa Maria - UFSM, Santa Maria, Brasil.

Received 2 October 2012. Published as resubmitted by the authors 28 February 2012. 